\title{
EFFICIENT MOLYBDENUM CATALYZED CHEMOSELECTIVE, SOLVENT-FREE OXIDATION OF SULFIDES TO SULFONES AT ROOM TEMPERATURE
}

\author{
ALI DADASHI HADIGAVABAR*, KHALIL TABATABAEIAN, MOHAMMAD ALI ZANJANCHI, \\ MANOUCHEHR MAMAGHANI
}

Department of Chemistry, Faculty of Sciences, University of Guilan, P. O. Box: 41635-1914, Rasht, Iran

\begin{abstract}
An efficient and reusable molybdenum-based catalyst has been prepared by tethering dioxomolybdenumacetylacetonate complex, MoO (acac), via postsynthesis modification of zeolite beta. The catalyst has been characterized by Fourier-transform infrared spectroscopy (FTIR), X-ray diffraction (XRD), scanning electron microscopy-energy dispersive X-ray analysis (SEM-EDX) and inductively coupled plasma (ICP). The catalyst exhibited very high activity for the selective oxidation of sulfides to sulfones at room temperature. The catalyst can be recycled and reused four times without significant loss of activity.
\end{abstract}

Keywords: Molybdenum; immobilization; selective oxidation; solvent free; sulfide; sulfone.

\section{INTRODUCTION}

Sulfides are the most undesirable contaminants of industrial effluents. In aqueous medium, sulfides in the form of hydrogen sulfide, have corrosive effects on the equipment and constructions. ${ }^{1}$ Therefore, the removal of sulfide-containing pollutants from air and wastewaters is essential in chemical industries. ${ }^{2}$ Various methods such as adsorption, biological processes and catalytic oxidations have been used for removal of sulfides. ${ }^{3,4}$ Oxidative desulfurization (ODS) is known as the main route to remove sulfur compounds from petroleum fuels. ${ }^{5}$ The selective oxidation of sulfide to sulfone has attracted considerable interest because of the preparation of valuable synthetic intermediates ${ }^{6}$ and the desulfurization of fuels. ${ }^{7}$ Diverse biological activity of sulfone linked bis(heterocycles) are reported. ${ }^{8}$ Thiosulfonates have antimicrobial and fungicidal activities ${ }^{9}$ and used as sulfenylating agents. ${ }^{10}$ For the oxidation of sulfides to sulfones, a variety of oxidants such as $\mathrm{KMnO}_{4},{ }^{11}$ periodic acid, ${ }^{12}$ tert-butylhydroperoxide ${ }^{13}$ tetrabutylammoniumperoxymonosulfate, ${ }^{14}$ hydrogen peroxide, ${ }^{15}$ peroxotungstate complexes ${ }^{16}$ and $\mathrm{NaOCl},{ }^{17}$ have been used. Among these oxidants, aqueous hydrogen peroxide, is the best choice since it is a cheap, readily available reagent and produces water as a harmless byproduct. In the absence of catalyst, the oxidation reaction is very slow. To overcome this limitation, $\mathrm{H}_{2} \mathrm{O}_{2}$ in combination with various catalysts such as silica sulfuric acid, ${ }^{18} \mathrm{TiO}_{2},{ }^{19} \mathrm{H}_{3} \mathrm{BO}_{3},{ }^{20}$ cyanuric chloride, ${ }^{21} \mathrm{NH}_{4} \mathrm{Cl}^{22}$ and chromium substituted polyoxometalate ${ }^{23}$ has been used. On the other hand, molybdenum complexes are known as useful catalysts for the oxidation of organic substrates. ${ }^{24}$ Among them, Mo(VI) has attracted considerable interest due to its biochemical importance ${ }^{25}$ as well as the catalytic activity of molybdenyum (VI) complexes in various industrial processes such as olefin metathesis, ${ }^{26}$ ammoxidation of olefins ${ }^{27}$ and epoxidation of olefins. ${ }^{28}$ Moreover, Mo(VI) compounds such as $\mathrm{MoO}_{2} \mathrm{Cl}_{2},{ }^{29} \mathrm{MoO}_{3}{ }^{30}$ and dioxo-molybdenum(VI) complex ${ }^{31}$ are considered to be very effective catalysts for the oxidation of sulfides using hydrogen peroxide as an environmentally benign oxidant. Although homogeneous catalysts exhibit very high activity, an important drawback associated with such catalysts is difficult separation from the catalytic media. So the development of heterogeneous systems where the molybdenum is immobilized on the supports has been attracted much attention. ${ }^{32,33}$ Moreover, metal-zeolites have successfully applied in the catalytic oxidation reactions of sulfides. ${ }^{34-36}$ In this context, zeolite beta with superior physicochemical properties such as large pore size, high silicon to aluminum ratio, high acid strength and thermal stability could be a good scaffold for the immobilization of molybdenum species. In continuation of our recent work, ${ }^{37}$ herein anchoring of $\mathrm{MoO}_{2}(\mathrm{acac})_{2}$ onto zeolite beta through Schiff-base condensation reaction between 3-aminopropyltrethoxysilane (APTES) functionalized zeolite beta and 2 -pyridine carbaldehyde is reported (Scheme 1). The resultant material acts as an effective catalyst for the selective oxidation of sulfides using hydrogen peroxide under solvent-free condition at room temperature (Scheme 2).
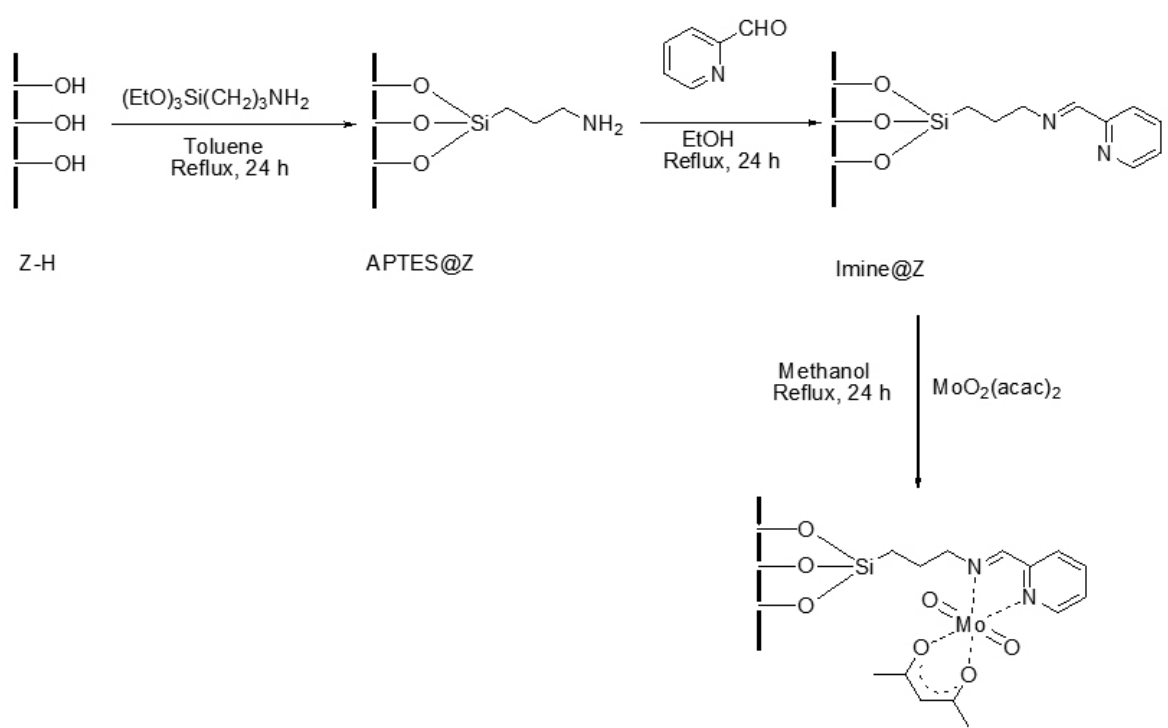

Scheme 1. Anchoring of molybdenum onto zeolite beta via coordinative attachment. 


\section{Mo@imine-Z (40 mg) \\ $\mathrm{R}^{1^{-S}} \mathrm{R}^{2}$

$\longrightarrow \begin{gathered}\mathrm{H}_{2} \mathrm{O}_{2}(2.5 \text { equiv. }) \\ \text { Solvent free, r.t., } 10-60 \mathrm{~min}\end{gathered} \mathrm{R}^{1^{-}} \mathrm{R}^{2}$

Scheme 2. Oxidation of sulfides to sulfones in the presence of Mo@ imine-Z.

\section{EXPERIMENTAL}

\subsection{Chemicals and instrumentation}

All solvents were obtained from Merck and used without further purification. 3-Aminopropyltriethoxysilane (APTES, 98\%), 2-pyridine carbaldehyde, tetraethylammoniumhydroxide (TEAOH, 20\%), sodium chloride $(99.5 \%)$, potassium chloride $(99.5 \%)$, sodium hydroxide $(98 \%)$ and $\mathrm{H}_{2} \mathrm{O}_{2}(30 \%$ in water) were purchased from Merck. Sodium aluminate $(56 \mathrm{wt} \%$ $\mathrm{Al}_{2} \mathrm{O}_{3}, 37 \mathrm{wt} \% \mathrm{Na}_{2} \mathrm{O}$ ) was supplied by Technical Company. $\mathrm{MoO}_{2}(\mathrm{acac})_{2}$ was obtained from Sigma Aldrich. Degussa aerosol was used for the synthesis of zeolite beta. Sulfides were purchased from Alfa Aesar. The powder X-ray diffraction (XRD) patterns of the samples were obtained on a Philips PW1840 diffractometer with $\mathrm{Cu}-\mathrm{K} \alpha$ radiation $\left(1.5418 \AA\right.$ ), in the range of $4-70^{\circ}$ at a scan rate of $0.1^{\circ} 2 \theta / \mathrm{s}$. SEM-EDX analyses were performed on a LEO $1430 \mathrm{VP}$ instrument. The molybdenum content was measured by inductively coupled plasma (ICP; Labtam 8440 plasma lab). The FTIR spectra of the samples were recorded using Bruker model Alpha spectrophotometer in $\mathrm{KBr}$ matrix in the range of $4000-400 \mathrm{~cm}^{-1}$. ${ }^{1} \mathrm{H}$ NMR spectra were recorded on a Bruker Avance spectrometer at $500 \mathrm{MHz}$, by using $\mathrm{CDCl}_{3}$ or DMSO-d, as solvent and TMS as internal reference. Melting points were determined on a BUCHI Melting point B-540 apparatus and are uncorrected.

\subsection{Catalyst preparation}

The catalyst was prepared according to the three step procedure shown in the reaction Scheme 1. The preparation of zeolite H-beta $(\mathrm{Z}-\mathrm{H})$, aminopropylated zeolite beta (APTES@Z) and imine-functionalized zeolite beta (Imine@Z) was described in our recent work. ${ }^{37}$ The molybdenum-bounded heterogeneous catalyst was prepared by stirring $2.0 \mathrm{~g}$ of the imine-functionalized zeolite H-beta with $\mathrm{MoO}_{2}(\mathrm{acac})_{2}(0.113 \mathrm{~g}, 0.5 \mathrm{mmol})$ in methanol $(20 \mathrm{~mL})$ under reflux condition for $24 \mathrm{~h}$. Then, the resulting solid was centrifuged and Soxhletextracted with ethanol and acetone and dried at $60{ }^{\circ} \mathrm{C}$ overnight, leading to molybdenum anchored zeolite H-beta (Mo@imine-Z, $2.04 \mathrm{~g}$ ) as a pale yellow powder. The metal loading in the catalyst was found to be $1.70 \mathrm{wt} \%$ based on ICP analysis.

2.3. General procedure for the oxidation of sulfides to sulfones

To a mixture of sulfide $(1 \mathrm{mmol})$ and catalyst $(0.04 \mathrm{~g}), \mathrm{H}_{2} \mathrm{O}_{2} 30 \%$ $(\mathrm{v} / \mathrm{v})(0.28 \mathrm{~g}, 2.5$ equiv. $)$ was added and stirred at room temperature for a specified time. After completion of the reaction, as indicated on thin-layer chromatography (TLC), ethyl acetate $(20 \mathrm{~mL})$ was added and the mixture was centrifuged to separate the catalyst. The filtrate was washed with brine and dried over anhydrous $\mathrm{Na}_{2} \mathrm{SO}_{4}$. Purification of the combined organics by preparative TLC (hexane-ethyl acetate, 10:1) provided pure products. The recycled catalyst was washed with ethyl acetate and acetone. After being dried at $60{ }^{\circ} \mathrm{C}$, it can be reused without further purification. All of the products were known and identified by comparison of their melting points and spectral data with those reported in the literature.

\subsection{Selected characterization data}

Diphenylsulfone: white solid; m.p.: $127-129^{\circ} \mathrm{C}$; Yield: $95 \%$; IR (KBr): v $=3071,1581,1443,1304,1156 \mathrm{~cm}^{-1} ;{ }^{1} \mathrm{H}$ NMR $\left(500 \mathrm{MHz}, \mathrm{CDCl}_{3}\right): \delta=7.49$ $(\mathrm{t}, j=7.47 \mathrm{~Hz}, 4 \mathrm{H}, \mathrm{Ar}-\mathrm{H}), 7.55(\mathrm{t}, j=7.27 \mathrm{~Hz}, 2 \mathrm{H}, \mathrm{Ar}-\mathrm{H}), 7.94(\mathrm{~d}, j=7.38 \mathrm{~Hz}$, $4 \mathrm{H}, \mathrm{Ar}-\mathrm{H}) \mathrm{ppm}$.

\section{3.}

\section{RESULTS AND DISCUSSION}

\subsection{Characterization of the heterogeneous catalyst}

The FTIR spectra of the zeolite H-beta (Z-H), aminopropylated zeolite beta (APTES@Z) and imine-functionalized zeolite beta (Imine@Z) were described in our recent work. ${ }^{37}$ The spectrum of the catalyst exhibit a broad band at 3437 $\mathrm{cm}^{-1}$ attributed to the $\mathrm{O}-\mathrm{H}$ stretching vibrations of surface silanol groups, a strong band at $1090 \mathrm{~cm}^{-1}$ due to the asymmetric $\mathrm{Si}-\mathrm{O}-\mathrm{Si}$ stretching vibrations and a band at $798 \mathrm{~cm}^{-1}$ corresponding to the symmetric Si-O-Si stretching modes. The expected vibration band for $\mathrm{C}=\mathrm{N}$ group was appeared at $1622 \mathrm{~cm}$ ${ }^{1}$, which indicated the involvement of azomethine nitrogen in coordination with metal center. Moreover, the appearance of two bands at 911 and $933 \mathrm{~cm}^{-1}$ for stretching vibrations of molybdenum oxide $(\mathrm{Mo}=\mathrm{O})$ further substantiate the immobilization of molybdenum complex onto zeolite (Figure1). ${ }^{32,38,39}$

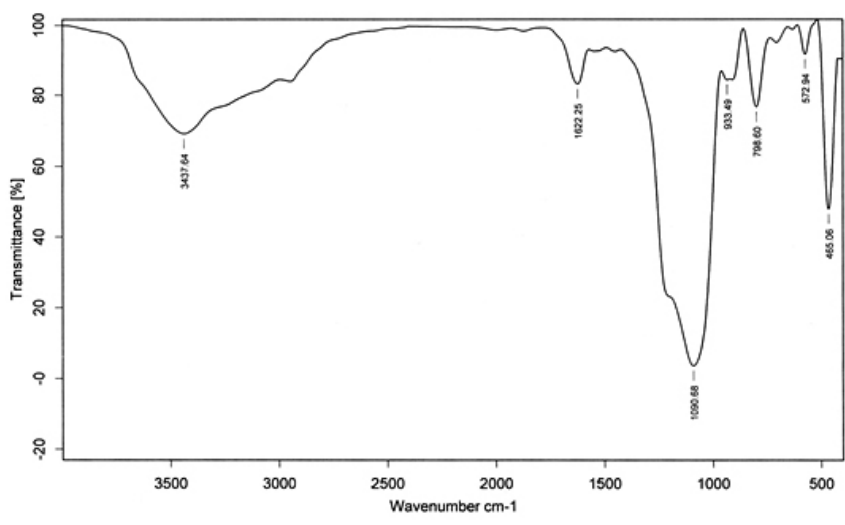

Figure 1. FT-IR spectrum of Mo@imine-Z.

The X-ray diffraction pattern of the catalyst is shown in Figure 2. The characteristic peaks of zeolite beta were observed in the XRD pattern. ${ }^{40}$ Since the changes in the peak positions are not prominent, it could be concluded that the crystallinity of zeolite matrix remains intact after molybdenum immobilization.

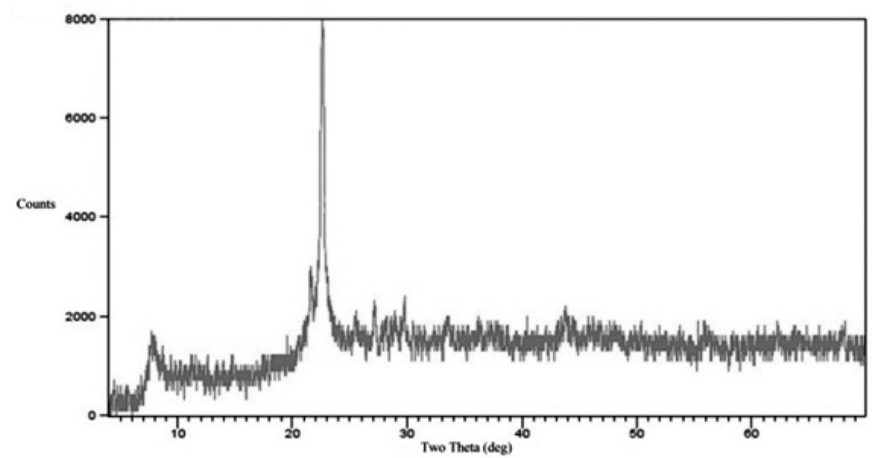

Figure 2. X-ray diffraction pattern of Mo@imine-Z.

SEM images of the synthesized zeolite and the prepared catalyst are shown in Figure 3. The images show that the crystal morphology has changed due to the surface modification. The presence of molybdenum caused a significant decrease in the zeolite particle size (Figure 3b).

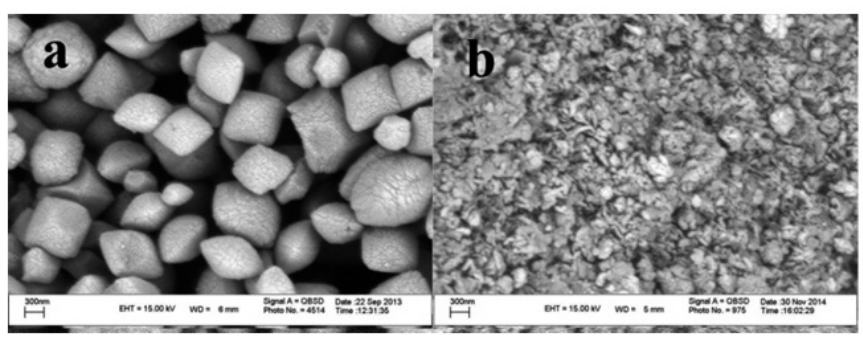

Figure 3. SEM images of (a) Z, (b) Mo@imine-Z.

In the EDX spectrum of the catalyst, the small peak for molybdenum clearly indicates that molybdenum is attached onto the surface of zeolite beta (Figure 4).

\subsection{Catalytic activity}

To find out the optimum reaction condition, the oxidation of diphenyl sulfide using 30\% aqueous solution of hydrogen peroxide in the presence of catalyst was examined as a model reaction. The results are shown in Table 1. Firstly, to optimize the quantity of the oxidant, this model reaction was carried out using 1.2, 2 and 2.5 equivalents of $\mathrm{H}_{2} \mathrm{O}_{2}$ in the presence of the catalyst (20 $\mathrm{mg}$ ). The reaction yield was affected crucially by the oxidant amount. The best amount of the oxidant for higher yields of sulfone was 2.5 equivalents (Table 1, Entries 1-3). Then the effect of the amount of catalyst was investigated. By 
raising the catalyst amounts, oxidation of diphenyl sulfide was increased (Table 1, Entries 4-5). When we carried out a blank reaction using $\mathrm{H}_{2} \mathrm{O}_{2}$ (2.5 equiv.) in the absence of catalyst, the reaction was not completed and a low yield of corresponding sulfone was formed (Table 1, Entry 6). The effect of solvent was investigated for the diphenyl sulfide oxidation under reflux condition. As seen in Table 1, in the presence of EtOH and $\mathrm{CH}_{3} \mathrm{CN}$ as solvent, the sole product is sulfone (Table 1, Entries 7-10). In order to study the effect of the oxidizing agent in the oxidation reaction, TBHP and $\mathrm{H}_{2} \mathrm{O}_{2}$ were used. From the economical and environmental point of view, solvent-free condition using hydrogen peroxide as oxidant ( 2.5 equiv.) and catalyst $(40 \mathrm{mg}$ ) was chosen as the best reaction condition (Table 1, Entry 5, Scheme 2).

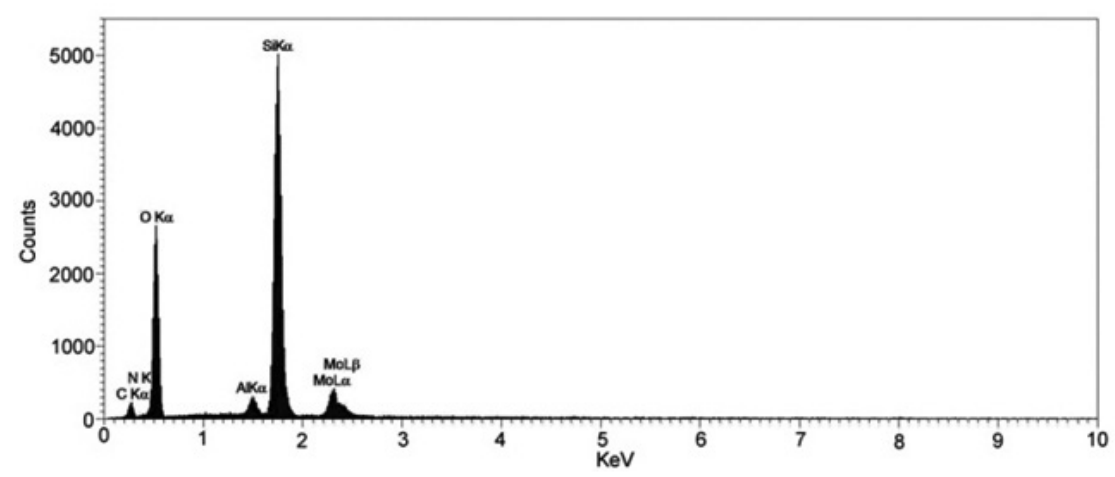

Figure 4. EDX analysis of Mo@imine-Z.

Table 1. Optimization of reaction condition for the oxidation of diphenyl sulfide.

\begin{tabular}{|c|c|c|c|c|c|c|c|}
\hline \multirow{2}{*}{ Entry } & \multirow{2}{*}{ Catalyst (mg) } & \multirow{2}{*}{ Oxidant (equiv.) } & \multirow{2}{*}{ Solvent } & \multirow{2}{*}{ Temperature $\left({ }^{\circ} \mathrm{C}\right)$} & \multirow{2}{*}{ Time (min) } & \multicolumn{2}{|c|}{ Isolated yields (\%) } \\
\hline & & & & & & Sulfoxide & Sulfone \\
\hline 1 & 20 & $\mathrm{H}_{2} \mathrm{O}_{2}(1.2)$ & - & r.t. & 45 & Trace & 50 \\
\hline 2 & 20 & $\mathrm{H}_{2} \mathrm{O}_{2}(2)$ & - & r.t. & 45 & Trace & 60 \\
\hline 3 & 20 & $\mathrm{H}_{2} \mathrm{O}_{2}(2.5)$ & - & r.t. & 45 & Trace & 65 \\
\hline 4 & 30 & $\mathrm{H}_{2} \mathrm{O}_{2}(2.5)$ & - & r.t. & 30 & Trace & 85 \\
\hline 5 & 40 & $\mathrm{H}_{2} \mathrm{O}_{2}(2.5)$ & - & r.t. & 30 & Trace & 95 \\
\hline 6 & - & $\mathrm{H}_{2} \mathrm{O}_{2}(2.5)$ & - & r.t. & 240 & Trace & 20 \\
\hline 7 & 40 & $\mathrm{H}_{2} \mathrm{O}_{2}(2.5)$ & $\mathrm{EtOH}$ & 80 & 15 & - & 90 \\
\hline 8 & 40 & $\mathrm{H}_{2} \mathrm{O}_{2}(2.5)$ & $\mathrm{CH}_{3} \mathrm{CN}$ & 80 & 15 & - & 85 \\
\hline 9 & 40 & TBHP (2.5) & EtOH & 80 & 15 & - & 85 \\
\hline 10 & 40 & TBHP (2.5) & $\mathrm{CH}_{3} \mathrm{CN}$ & 80 & 15 & - & 80 \\
\hline
\end{tabular}

With the optimized condition in hand, oxidation of various aromatic and aliphatic sulfides was performed. The results are summarized in Table 2. Various sulfides such as diaryl, dibenzyl, dialkyl, diallyl and arylbenzyl were selectively oxidized to the corresponding sulfones. With regard to the aliphatic sulfides, however, the present method showed longer reaction times and lower yields (Table 2, Entries 9-10). To evaluate the chemoselectivity of the catalytic system, sulfides containing sensitive functional groups such as diallyl sulfide, 2-hydroxyethyl phenyl sulfide, 4-(methylthio)benzaldehyde and benzothiophene were subjected to the sulfoxidation reaction and it was observed that these reactive functional groups remained intact during the reaction (Table 2, Entries 4, 5, 8, 9)

Table 2. Selective oxidation of sulfides to the corresponding sulfones.

\begin{tabular}{|c|c|c|c|c|c|c|}
\hline \multirow{2}{*}{ Entry } & \multirow{2}{*}{ Substrate } & \multirow{2}{*}{ Time (min) } & \multirow{2}{*}{ Yield $(\%)^{\mathrm{a}}$} & \multicolumn{2}{|c|}{ M.P. $\left({ }^{\circ} \mathrm{C}\right)$} & \multirow{2}{*}{ References } \\
\hline & & & & Found & Reported & \\
\hline 1 & Diphenyl sulfide & 30 & 95 & $127-129$ & $128-129$ & [41] \\
\hline 2 & Dibenzyl sulfide & 20 & 90 & $148-150$ & $148-151$ & [18] \\
\hline 3 & Benzyl phenyl sulfide & 30 & 92 & $142-144$ & $142-144$ & [18] \\
\hline 4 & $4,4^{\prime}$-thiodiphenol & 50 & 94 & $245-247$ & $245-247$ & [42] \\
\hline 5 & 2-hydroxyethyl phenyl sulfide & 60 & 90 & - & - & [41] \\
\hline 6 & Benzothiophene & 30 & 94 & $140-142$ & $141-143$ & [43] \\
\hline 7 & Dibenzothiophene & 45 & 90 & $231-233$ & $232-232.5$ & [41] \\
\hline 8 & 4-(methylthio) benzaldehyde & 10 & 94 & $158-160$ & $155-161$ & [42] \\
\hline 9 & Diallyl sulfide & 60 & 88 & - & - & [41] \\
\hline 10 & Dibutyl sulfide & 50 & 88 & $42-44$ & $46-46.5$ & [41] \\
\hline
\end{tabular}


Note: All products were characterized by ${ }^{1} \mathrm{H}$ NMR and IR data and Identified by comparison with authentic samples. ${ }^{a}$ Yields refer to the isolated pure products.

A plausible mechanism for this oxidation reaction is presented in Scheme

3. As shown, prior coordination of hydrogen peroxide to molybdenum, polarizes the $\mathrm{O}-\mathrm{O}$ bond in $\mathrm{H}_{2} \mathrm{O}_{2}$ and gives intermediate $\mathrm{I}$. Oxygen transfer between intermediate I and sulfide followed by loss of water gives sulfoxide and the catalyst backs to its original structure. This catalytic cycle was repeated again and after loss of second molecule of water, sulfone as a final product is obtained.

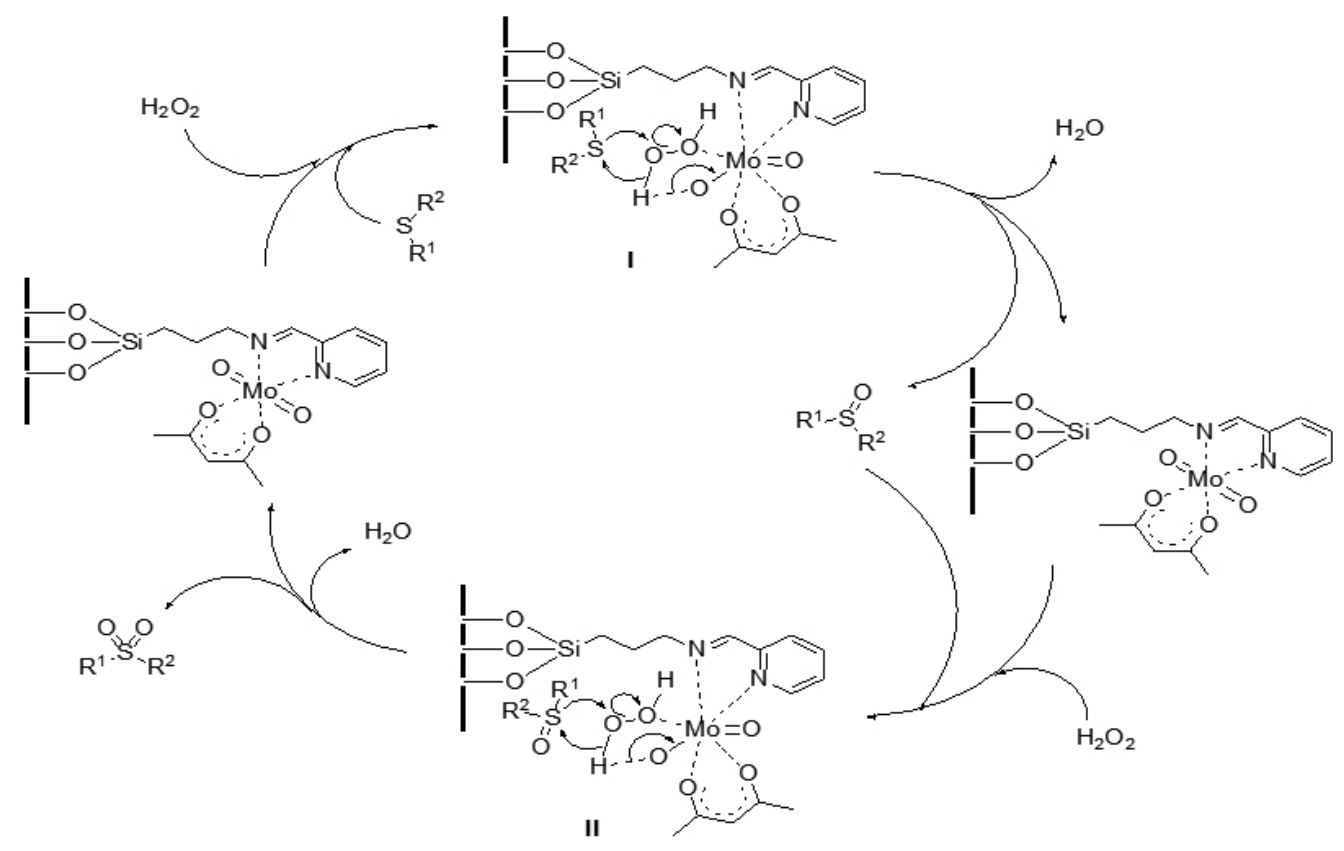

Scheme 3. A plausible mechanism for the oxidation of sulfides in the presence of Mo@imine-Z.

In order to demonstrate the efficiency of this method, our results on the oxidation of diphenyl sulfide were compared with some of those reported in the literature (Table 3). As shown in Table 3, the present protocol is comparable with several of the others.

Table 3. Comparison of our results with those obtained using other catalysts for the oxidation of diphenyl sulfide.

\begin{tabular}{|c|c|c|c|c|c|}
\hline Entry & Catalyst (amount) & Condition & Time (min) & Yield (\%) & References \\
\hline 1 & peroxotungstate complexes ( $2 \mathrm{~mol} \%)$ & $\begin{array}{c}\mathrm{H}_{2} \mathrm{O}_{2}, \mathrm{CH}_{2} \mathrm{Cl}_{2}: \mathrm{CH}_{3} \mathrm{OH}, \\
12^{\circ} \mathrm{C} .\end{array}$ & 420 & $84.4^{\mathrm{a}}$ & {$[16]$} \\
\hline 2 & silica sulfuric acid $(0.2 \mathrm{~g})$ & $\mathrm{H}_{2} \mathrm{O}_{2}, \mathrm{CH}_{3} \mathrm{CN}$, r.t. & 45 & 95 & {$[18]$} \\
\hline 3 & $\mathrm{MoO}_{3}(0.05$ equiv. $)$ & $\mathrm{H}_{2} \mathrm{O}_{2}, \mathrm{EtOH}, 50{ }^{\circ} \mathrm{C}$ & 40 & 97 & {$[30]$} \\
\hline 4 & $\mathrm{MoO}_{2} \mathrm{Cl}_{2}(15 \mathrm{~mol} \%)$ & $\mathrm{H}_{2} \mathrm{O}_{2}, \mathrm{CH}_{3} \mathrm{CN}$, r.t. & 35 & 91 & {$[29]$} \\
\hline 5 & cyanuric chloride (1 equiv.) & $\mathrm{H}_{2} \mathrm{O}_{2}, \mathrm{CH}_{3} \mathrm{CN}$, r.t. & 25 & 96 & {$[21]$} \\
\hline 6 & $\mathrm{H}_{3} \mathrm{BO}_{3}(20 \mathrm{~mol} \%)$ & $\mathrm{H}_{2} \mathrm{O}_{2}$, solvent-free, r.t. & 25 & 95 & {$[20]$} \\
\hline 7 & silica-vanadia ( 0.0043 equiv.) & $\mathrm{H}_{2} \mathrm{O}_{2}, \mathrm{CH}_{3} \mathrm{OH}$, r.t. & 20 & 90 & {$[15]$} \\
\hline 8 & Mo@imine-Z (40 mg) & $\mathrm{H}_{2} \mathrm{O}_{2}$, solvent-free, r.t. & 30 & 95 & This work \\
\hline
\end{tabular}

a GC yield.

Catalyst reusability

Reusability of the catalyst was examined in the oxidation of diphenyl sulfide under solvent-free condition as a model reaction. The catalyst was separated after each run, washed with ethyl acetate and acetone, dried in an oven at $60^{\circ} \mathrm{C}$ and reused in subsequent runs. After four successive runs, the catalytic activity of the catalyst was maintained without significant loss of the activity (Table 4).

Table 4. Reusability of the catalyst in the oxidation of diphenyl sulfide.

\begin{tabular}{|c|c|}
\hline Run Number & Yield (\%) \\
\hline 1 & 95 \\
\hline 2 & 94 \\
\hline 3 & 92 \\
\hline 4 & 90 \\
\hline
\end{tabular}




\section{CONCLUSION}

In brief, we have demonstrated that molybdenum supported on zeolite beta was a novel and effective heterogeneous catalyst for the oxidation of sulfides under solvent-free condition. Mild reaction condition, chemoselectivity, reusability of the catalyst, high yields of the products and lower reaction times are the main merits of this methodology.

\section{ACKNOWLEDGMENT}

We are grateful to the Research Council of University of Guilan for their partial support

\section{REFERENCES}

1.- J. E. Burgess, S. A. Parsons, R. M. Stuetz, Biotechnol. Adv.19, 35, (2001)

2.- L. Zhang, P. De Schryver, B. De Gusseme, W. De Muynck, N. Boon, W. Verstraete, Water Res. 42, 1 (2008)

3.- A. Alonso Vicario, J. R. Ochoa Gomez, S. Gil Rio, O. Gomez Jimenez Aberasturi, C. A. Ramirez Lopez, J. Torrecilla Soria, A. Dominguez, Microporous Mesoporous Mater. 134, 100, (2010)

4.- Y. L. Ng, R. Yan, X. G. Chen, A. L. Geng, W. D. Gould, D. T. Liang, L. C. C. Koe, Appl. Microbiol. Biotechnol. 66, 259, (2004)

5.- W. Zhu, G. Zhu, H. Li, Y. Chao, Y. Chang, G. Chen, C. Han, J. Mol. Catal. A Chem. 347, 8 (2011)

6.- O. De Lucchi, D. Fabbri, V. Lucchini, Tetrahedron 48, 1485, (1992)

7.- D. Wang, E. W. Qian, H. Amano, K. Okata, A. Ishihara, T. Kabe, Appl. Catal. A Gen. 253, 91 (2003)

8.- V. Padmavathi, K. Mahesh, D. R. C. Venkata Subbaiah, D. Deepti, G. S. Reddy, ARKIVOC x, 195, (2009)

9.- J. P. Weidner, S. S. Block, J. Med. Chem. 7, 671, (1964)

10.- K. Fujiki, E. Y. Yoshida, Synth. Commun. 29, 3289 (1999)

11.- G. W. Gokel, H. M. Gerdes, D. M. Dishong, J. Org. Chem. 45, 3634, (1980)

12.- D. H. R. Barton, W. Li, J. A. Smith, Tetrahedron Lett. 39, 7055, (1998)

13.- P. J. Kropp, G. W. Breton, J. D. Fields, J. C. Tung, B. R. Loomis, J. Am. Chem. Soc. 122, 4280, (2000)

14.- N. Iranpoor, D. Mohajer, A. R. Rezaeifard, Tetrahedron Lett. 45, 3811 (2004)

15.- F. Gregori, I. Nobili, F. Bigi, R. Maggi, G. Predieri, G. Sartori, J. Mol. Catal. A Chem. 286, 124, (2008)

16.- S. X. Ying, W. J. Fa, J. Mol. Catal. A Chem. 280, 142 (2008)

17.- N. Fukuda, T. Ikemoto, J. Org. Chem. 75, 4629, (2010)

18.- A. Shaabani, A. H. Rezayan, Catal. Commun. 8, 1112, (2007)

19.- W. Al Maksoud, S. Daniele, A. B. Sorokin, Green Chem. 10, 447, (2008)

20.- A. Rostami, J. Akradi, Tetrahedron Lett. 51, 3501, (2010)

21.- K. Bahrami, M. M. Khodaei, S. Sohrabnezhad, Tetrahedon Lett. 52, 6420, (2011)

22.- Q. Xue, Z. Mao, Y. Shi, H. Mao, Y. Cheng, C. Zhu, Tetrahedron Lett. 53, 1851, (2012)

23.- R. Afrasiabi, F. Jalilian, B. Yadollahi, M. Riahi Farsani, Inorg. Chem. Commun. 50, 113, (2014)

24.- B. Meunier, Metal-Oxo and Metal-Peroxo Species in Catalytic Oxidations, Springer, Berlin, 2000.

25.- S. Metz, W. Thiel, Coord. Chem. Rev. 255, 1085 (2011)

26.- K. J. Ivin, J. C. Mol, Olefin Metathesis and Metathesis Polymerisation, Academic Press, London, 1997.

27.- R. K. Grasselli, Catal. Today, 49, 141, (1999)

28.- R. J. Cross, P. D. Newman, R. D. Peacock, D. Stirling, J. Mol. Catal. A Chem. 144, 273, (1999)

29.- K. Jeyakumar, D. K. Chand, Tetrahedron Lett. 47, 4573, (2006)

30.- M. M. Khodaei, K. Bahrami, M. Khedri, Can. J. Chem. 85, 7, (2007)

31.- I. Sheikhshoaie, A. Rezaeifard, N. Monadi, S. Kaafi, Polyheron 28, 733, (2009)

32.- R. K. Sharma, A. Pandey, S. Gulati, Polyhedron, 45, 86, (2012)

33.- V. Palermo, G. P. Romanelli, P. G. Vazquez, Phosphorus Sulfur Silicon Relat. Elem. 184, 3258, (2009)

34.- T. I.Reddy,R. S.Varma, Chem. Commun.471, (1997)

35.- A. Fuerte, M. Iglesias, F. Sanchez, A. Corma, J. Mol. Catal. A Chem. 211, 227, (2004)

36.- Y. Kon, T. Yokoi, M. Yoshioka, S. Tanaka, Y. Uesaka, T. Mochizuki, K. Sato, T. Tatsumi, Tetrahedron 70, 7584, (2014)
37.- K. Tabatabaeian, M. A. Zanjanchi, M. Mamaghani, A. Dadashi, Can. J. Chem. 92, 1086, (2014)

38.- F. Esnaashari, M. Moghadam, V. Mirkhani, S. Tangestaninejad, I. Mohamadpoor Baltork, A. R. Khosoropoor, M. Zakeri, S. Hushmandrad, Polyhedron 48, 212, (2012)

39.- F. Esnaashari, M. Moghadam, V. Mirkhani, S. Tangestaninejad, I. Mohammadpoor Baltork, A. R. Khosoropour, M. Zakeri, Mater. Chem. Phys. 137, 69, (2012)

40.- H. Robson, Verified Synthesis of Zeolitic Materials, Elsevier, Amesterdam, 2001.

41.- K. Sato, M. Hyodo, M. Aoki, X. Q. Zheng, R. Noyori, Tetrahedron 57, $2469,(2001)$

42.- C. J. Pouchert, J. Behnke, The Aldrich Library of ${ }^{13} \mathrm{C}$ and ${ }^{1} \mathrm{H}$ FT NMR Spectra, Aldrich Chemical:Milwaukee, 1993.

43.- D. Madec, F. Mingoia, C. Macovei, G. Maitro, G. Giambastiani, G. Poli, Eur. J. Org. Chem. 552, (2005) 